Article

\title{
Improvements in Physical Activity Levels after the Implementation of an Active-Break-Model-Based Program in a Primary School
}

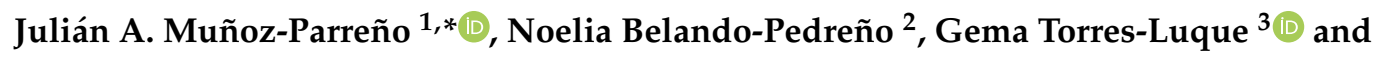 \\ Alfonso Valero-Valenzuela ${ }^{1}(\mathbb{D}$ \\ 1 Health, Physical Activity and Education (SAFE), Faculty of Sport Sciences, University of Murcia, \\ 30720 Santiago de la Ribera, Spain; avalero@um.es \\ 2 Departament of Sport Sciences, Universidad Europea de Madrid, Villaviciosa de Odón, 28670 Madrid, Spain; \\ noelia.belando@universidadeuropea.es \\ 3 Departamento de Didáctica de la Expresión Corporal, University of Jaén, 23071 Jaén, Spain; gtluque@ujaen.es \\ * Correspondence: r6.julian@gmail.com; Tel.: +34-625-45-9000
}

Received: 29 March 2020; Accepted: 24 April 2020; Published: 28 April 2020

check for updates

\begin{abstract}
The aim of this study was to analyze changes in the physical activity levels in students after implementing an active break (AB)-model-based program during the school day. Forty-four fifth-grade primary school children ( 24 boys, 20 girls, with a mean age $=10.44 \pm 0.45$ ) participated in a 17 week program. After intervention, there was an increase in moderate and vigorous total activity during physical education lessons, non-physical education lessons, and recesses. Intervention programs to encourage physical activity and decrease sedentary time are recommended.
\end{abstract}

Keywords: accelerometry; primary school; active learning; health

\section{Introduction}

Nowadays, the value of physical activity (PA) is beyond question, and international organizations such as the World Health Organization (WHO) [1] have supported this view. It stated that young people between five and 17 years of age should do at least 60 min of moderate to vigorous physical activity (MVPA) to have good overall health. However, this recommendation seems not to have been put into practice amongst children between six and 12 years of age. Studies have shown that there has been a gradual increase in young peoples' sedentary behavior [2-6].

A scholarly environment is perhaps the ideal place to increase the daily PA of students. There are periods in the school day when sporting and physical involvement can be enhanced; for example: Commuting to and from school, in physical education (PE) and non-PE lessons, in class changeovers, and recesses [2,7]. It has been suggested that schoolchildren spend too much time sitting and are hardly ever encouraged to move outside of PE [8]. Faced with this problem, the design of new methodological strategies, such as active breaks (ABs), could help to increase the motor action time. These ABs consist of doing active pauses or micro-pauses in conventional lessons to include short periods of PA as part of the curriculum [9]. The goal of the ABs is to reduce the sedentary lifestyle of schoolchildren [10].

There has been a considerable amount of research demonstrating the effectiveness of ABs in classrooms. In the physical dimension, students naturally improve their level of activity [11-14], avoiding weight gain and even making it possible to reduce it [15-18], as well as experiencing fewer symptoms of pain in the intervertebral joints of the cervical and lumbar region of the spine [19]. In the behavioral dimension, more enjoyment of learning has been observed [20], as well as less distraction during the tasks in the classroom [21]. In the cognitive dimension, it has led to further information 
retention, with students applying what they have learned and paying greater attention to subsequent tasks [22]. Finally, ABs help to improve the overall health of young students [11-14].

Based on this evidence, the need arises in the present study to check whether ABs carried out in conventional classes generate any change in MVPA levels at other times of the school day in which physical activity is a feature; for example, during PE lessons and recesses.

Taking into account the literature reviewed above and the problem of sedentary lifestyles found in the school population, it is necessary to propose interventional methodologies at an early age to allow the development of specific activities that increase MVPA levels. Therefore, the objective of this study was to analyze changes in the PA levels of schoolchildren after using ABs as an intervention throughout the school day, including during PE lessons and recesses. It was hypothesized that the group of schoolchildren who received the ABs would engage in higher MVPA throughout the school day and in different periods compared with the group that did not participate in the ABs.

\section{Materials and Methods}

\subsection{Participants}

A quasi-experimental design study (pre-test, post-test) with a longitudinal section was undertaken, in which a total of 44 Hispanic primary school children between the ages of nine and eleven years $(M=10.44 ; S D=0.45)$ participated. An educational center was selected for accessibility and convenience. Two natural groups were chosen at random and were divided into an experimental group $(N=22$; 12 males) and a control group ( $N=22 ; 12$ males). Although the study was not double-blinded, some actions were taken into account to minimize the experimental bias. One of them was to randomly choose the students in the experimental and control groups to wear the accelerometers. Furthermore, the researcher bias was controlled in that he did not participate in the ABs model-based program's implementation and or in helping students put the devices on and taking them off. The students belonged to a public school with a medium socioeconomic level. The inclusion and exclusion criteria used to participate in the research were regular attendance in classes and no physical limitations with regard to physical activity. Written informed consent was obtained from parents or guardians of all children prior to their participation and after a briefing. The ethics committee of the local institution approved the study.

\subsection{Intervention Design}

To begin, a briefing session was organized, in which the researcher explained the objectives and plan of the study. Participation was requested. Each group involved (experimental and control) was assigned a teacher according to accessibility and convenience. The teacher applied the ABs program in the experimental group, while in the PE control group, all lessons were conducted normally. No variables were manipulated. However, the same unit contents were taught in both groups; the schedule is described in Figure 1.

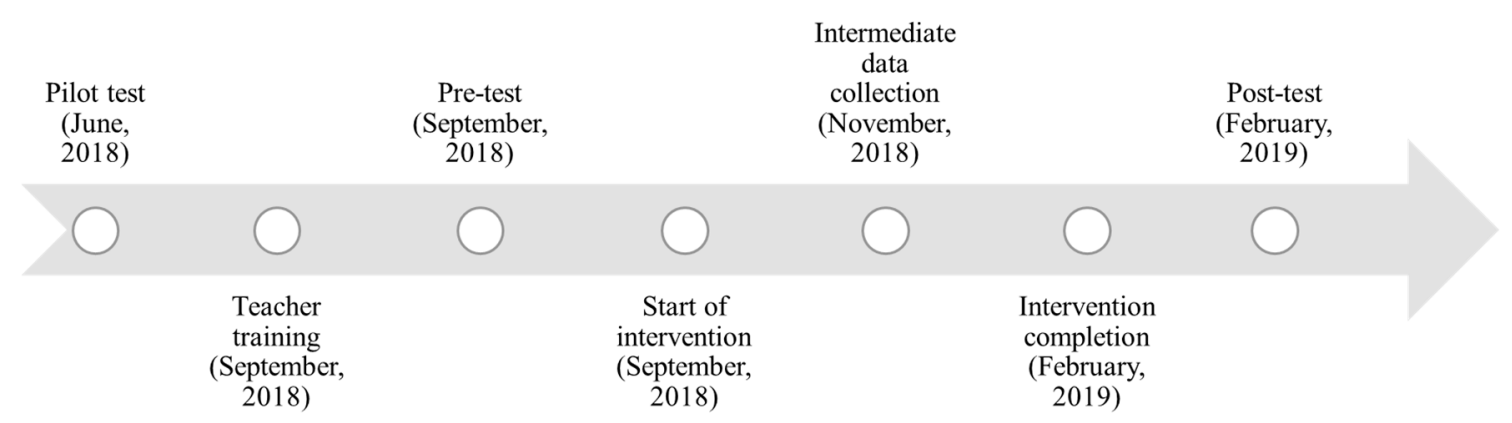

Figure 1. Schedule of the study. 
A pilot program was released in June 2018. This served to improve the actual program's overall design, and videos were produced for teacher training. Two training sessions for the teacher of the experimental group were held in the first week of September 2018. Each one lasted two and a half hours. The content of the first session comprised the program's basic features: High-intensity interval training (HIIT) and the ABs methodology. During the second session, strategies were demonstrated for the teaching of the curricular contents and for the integration of the ABs. Examples of physical exercises and lessons to be delivered using PowerPoint were demonstrated. Practical training was given in the second week (Monday to Friday). ABs in each subject, proposed exercises, organization of the students, and informational sessions (with PowerPoint) were also featured. The principal researcher was with the teacher for one hour each day.

The intervention itself took place over 17 weeks, for five days a week (82 days in total, three of them were holidays). Mathematics (seven hours a week), language (six hours a week), natural sciences (three hours a week), social sciences (three hours a week), and plastics (once a week) lessons incorporated $328 \mathrm{AB}$ periods, lasting five to ten minutes. They were introduced 15-20 min after the beginning of each session, in line with earlier recommendations [23]. Each AB had three options: HIIT + academic content; HIIT + emotional intelligence (EI) content; and HIIT + academic content + team work. The entire training program had been endorsed by various researchers in its HIIT and Tabata modalities [24,25]. The AB combinations were:

1. Two twice-daily sessions of HIIT + academic content, where ABs were applied in language and literature (once a week), mathematics (twice a week), natural sciences (three times a week), social sciences (three times a week), and plastics (once a week) lessons. In general, the exercises were: Squats, strides, push-ups, triceps and biceps work, jumps, chair climbs, sit-ups, plantar stretching, burpees, jumping jacks, mountain climbing, and so on, always in bursts of $20 \mathrm{~s}$ with a $15 \mathrm{~s}$ rest.

2. One session of HIIT + IE content [26,27], where ABs were applied in language and literature lessons once a day, for five days a week.

3. One session of HIIT + academic content + team work, where ABs were applied in mathematics lessons once a day, for five days a week. Team work consisted of the whole class cooperating to gain collective points [28]. For example, in mathematics lessons (one a day for five days of the week), the teacher wrote a number of problems to be solved on the blackboard, and the whole group had to meet the challenge (e.g., 1000 squats in five minutes).

Every day from Monday to Friday, students received two sessions of HITT + academic content, one session of HITT + IE, and one session of HIIT + academic content + team work, which means four $\mathrm{ABs}$ per day and $20 \mathrm{ABs}$ per week.

\subsection{Procedures and Measurements}

ActiGraph wGT3X-BT $(N=14)$ and ActiGraph GT3X $(N=30)$ (ActiGraph, Pensacola, Florida, USA) accelerometers were used to measure PA each day of the week (between 9:00 am and 14:00 $\mathrm{pm})$. The numbers of the accelerometer models were the same in both groups. Data were recorded at three different points (a prior phase, an intermediate phase, and after the intervention program). The accelerometers store information on three orthogonal axes: $Y$ (vertical), $X$ (horizontal right-left), and $\mathrm{Z}$ (horizontal front-back). In addition, they have a supporting software option called a magnitude vector, which is defined as the square root of the squared sum of each axis. All devices had been tested previously for their validity and reliability in measuring PA $[29,30]$. The accelerometers were fastened by an elastic belt and placed next to the right hip of the participants [31], who kept a weekly diary in which they wrote down their PE and recess activities.

The data were considered valid when the registration was equivalent to or more than four hours a day over four days a week. A total of 12 participants (four in the experimental group and eight in the control group) were excluded at different phases of the study. Data were downloaded and analyzed using the ActiLife 6.8.0 (ActiGraph, Pensacola, Florida, USA) software, with $60 \mathrm{~Hz}$ for the 
accelerometer wGT3X-BT and a one-second epoch for the accelerometer ActiGraph GT3X. The cut-off points proposed by Evenson et al. (2008) were used: Sedentary PA, 0-100 counts/minute; light PA, 101-2295 counts/minute; moderate PA, 2296-4011 counts/minute; and vigorous, $>4012$ counts/minute. In addition, PA levels were calculated by minutes per day by dividing each PA level by the valid number of days recorded. For each activity, the percentage contribution in minutes/day was averaged according to international health recommendations [1], which are $60 \mathrm{~min} /$ day of MVPA (MVPA $\times$ $100 / 60)[2,32]$.

\subsection{Data Analysis}

All variables were shown as mean, standard deviation, frequency, and percentage. A Shapiro-Wilk test indicated the non-normality of the data. This test is recommended in samples with below 50 participants [33]. Comparisons of the experimental versus control group were conducted using the Mann-Whitney $\mathrm{U}$ test. The level of significance was set at $p \leq 0.05$. The monitoring of each group was performed with the Wilcoxon test. The magnitude of the differences between the research groups was obtained by means of the effect size [34], where $d=0.20$ is small, $d=0.50$ is moderate, and $d=0.80$ is high. Analyses were conducted with IBM SPSS 25 (Armonk, New York, USA) software.

\subsection{Ethical Approval}

The Ethics Committee of the University of Murcia (Spain) approved this study (ID: 2036/2018).

\section{Results}

Statistical analysis of PA levels through the Mann-Whitney $U$ test revealed no significant differences $(p<0.05)$ in measured PA variables between the control group and the experimental group in the pre-test phase (i.e., prior to the intervention with the ABs) (Table 1). 
Table 1. Level of physical activity undertaken during class hours.

\begin{tabular}{|c|c|c|c|c|c|c|c|c|c|c|c|c|c|c|c|c|c|c|c|c|}
\hline & & & \multicolumn{4}{|c|}{ Pre-Intervention } & \multicolumn{7}{|c|}{ Inter-Intervention } & \multicolumn{5}{|c|}{ Post-Intervention } & \multirow[b]{3}{*}{$p$} & \multirow[b]{3}{*}{$d$} \\
\hline & & & \multicolumn{2}{|c|}{ Control } & \multicolumn{2}{|c|}{ Experimental } & \multirow[b]{2}{*}{$p$} & \multirow[b]{2}{*}{$d$} & \multicolumn{2}{|c|}{ Control } & \multicolumn{2}{|c|}{ Experimental } & \multirow[b]{2}{*}{$p$} & \multirow[b]{2}{*}{$d$} & \multicolumn{2}{|c|}{ Control } & \multicolumn{2}{|c|}{ Experimental } & & \\
\hline & & & $M$ & $S D$ & $M$ & $S D$ & & & $M$ & $S D$ & $M$ & $S D$ & & & $M$ & $S D$ & $M$ & $S D$ & & \\
\hline \multirow{5}{*}{$\begin{array}{l}\text { School } \\
\text { day }\end{array}$} & Sedentary & (min/day) & 197.24 & 16.01 & 197.47 & 16.39 & 0.736 & 0.01 & 247.62 & 20.23 & 215.99 & 31.53 & $0.000 * *$ & -1.19 & 242.33 & 17.18 & 222.79 & 20.33 & $0.002 * *$ & -1.04 \\
\hline & Light & $(\mathrm{min} /$ day $)$ & 29.40 & 13.11 & 29.22 & 13.30 & 0.955 & -0.01 & 36.24 & 18.45 & 50.88 & 23.17 & $0.011 *$ & 0.70 & 39.79 & 15.40 & 42.48 & 14.89 & 0.311 & 0.18 \\
\hline & Moderate & (min/day) & 6.36 & 2.74 & 6.68 & 2.29 & 0.613 & 0.13 & 6.70 & 2.30 & 12.59 & 3.66 & $0.000 * *$ & 1.93 & 8.26 & 2.15 & 9.92 & 2.78 & $0.033 *$ & 0.67 \\
\hline & Vigorous & (min/day) & 5.26 & 2.49 & 5.68 & 3.68 & 0.779 & 0.13 & 6.65 & 2.75 & 15.23 & 3.88 & $0.000 * *$ & 2.55 & 8.20 & 3.28 & 10.32 & 3.99 & $0.023 *$ & 0.60 \\
\hline & MVPA & (min/day) & 11.62 & 4.84 & 12.36 & 5.55 & 0.866 & 0.14 & 13.32 & 4.44 & 27.82 & 6.36 & $0.000 * *$ & 2.64 & 16.46 & 5.07 & 20.23 & 6.02 & $0.020 *$ & 0.68 \\
\hline \multirow[t]{5}{*}{ PE } & Sedentary & (min/day) & 23.96 & 2.53 & 22.59 & 3.12 & 0.238 & -0.48 & 28.57 & 5.45 & 24.18 & 5.45 & $0.021 *$ & -0.80 & 21.19 & 5.95 & 21.10 & 4.50 & 0.714 & -0.02 \\
\hline & Light & & 6.05 & 2.11 & 6.96 & 2.80 & 0.407 & 0.37 & 10.14 & 3.84 & 12.89 & 5.73 & 0.052 & 0.56 & 14.64 & 3.97 & 14.66 & 3.31 & 0.670 & 0.00 \\
\hline & Moderate & (min/day) & 1.29 & 0.57 & 1.61 & 0.60 & 0.100 & 0.55 & 2.84 & 1.11 & 3.73 & 1.13 & $0.028 *$ & 0.79 & 4.39 & 1.78 & 4.68 & 1.27 & 0.347 & 0.19 \\
\hline & Vigorous & (min/day) & 1.02 & 0.38 & 1.17 & 0.47 & 0.415 & 0.35 & 3.39 & 1.63 & 4.21 & 1.68 & 0.104 & 0.49 & 4.77 & 2.02 & 4.57 & 2.49 & 0.419 & -0.09 \\
\hline & MVPA & (min/day) & 2.30 & 0.84 & 2.78 & 0.84 & 0.095 & 0.57 & 6.23 & 2.35 & 7.94 & 2.11 & $0.035^{*}$ & 0.77 & 9.16 & 3.28 & 9.24 & 3.13 & 0.907 & 0.02 \\
\hline \multirow[t]{5}{*}{ Recess } & Sedentary & (min/day) & 12.10 & 4.87 & 13.80 & 5.50 & 0.339 & 0.33 & 14.91 & 3.99 & 11.56 & 4.61 & $0.029 *$ & -0.77 & 15.95 & 3.12 & 12.92 & 3.87 & $0.025^{*}$ & -0.86 \\
\hline & Light & (min/day) & 10.81 & 3.24 & 9.24 & 3.06 & 0.084 & -0.50 & 9.39 & 3.04 & 10.19 & 3.45 & 0.496 & 0.25 & 8.43 & 2.35 & 10.16 & 2.66 & $0.048^{*}$ & 0.70 \\
\hline & Moderate & (min/day) & 3.75 & 1.99 & 3.32 & 1.55 & 0.555 & -0.24 & 2.68 & 0.93 & 3.66 & 1.58 & $0.033 *$ & 0.76 & 2.64 & 0.94 & 3.32 & 1.19 & $0.015 *$ & 0.63 \\
\hline & Vigorous & (min/day) & 3.34 & 1.95 & 3.63 & 3.20 & 0.613 & 0.11 & 2.89 & 1.26 & 4.58 & 2.43 & $0.014 *$ & 0.87 & 2.97 & 1.19 & 3.59 & 2.10 & 0.472 & 0.36 \\
\hline & MVPA & (min/day) & 7.09 & 3.69 & 6.95 & 4.46 & 0.684 & -0.03 & 5.57 & 1.79 & 8.24 & 3.50 & $0.005^{* *}$ & 0.96 & 5.62 & 1.84 & 6.92 & 2.84 & 0.191 & 0.54 \\
\hline
\end{tabular}

Note: $\mathrm{M}=$ mean; $\mathrm{SD}=$ standard deviation; ${ }^{*} p<0.05 ; * *<0.01 \cdot \mathrm{d}=$ effect size (Cohen); School day $=$ school day $(9: 00$ am-14:00 pm); PE $=$ physical education classes; Recess $=$ integrated $30 \mathrm{~min}$ break in the school day; Sedentary, Moderate, Vigorous = physical activity levels (Evenson et al., 2008); MVPA = moderate to vigorous physical activity. 
However, significant differences were found in the data collected in the intermediate period, when the intervention program was in its realization phase (Table 1). These were in favor of the experimental group in the variables light PA, moderate, vigorous, and MVPA during the total weekly time. Significant differences were found in moderate PA, MVPA, and sedentary time in the experimental group. In addition, significant differences were observed in favor of the experimental group in the variables referred to the recess period in moderate and vigorous PA and MVPA. In the weekly sedentary time and sedentary time variables during recesses, significant results were obtained in favor of the control group.

In relation to the results obtained in PA after the conclusion of the program, significant differences were found associated with the control group in sedentary time during the school day and in sedentary time during recess periods. Regarding the experimental group, there were significant differences in moderate and vigorous PA specifically, as well as their totals (MVPA) over the week. If recess time is considered, significant differences were shown in light and moderate PA. No significant differences were found in the rest of the variables (Figure 2).

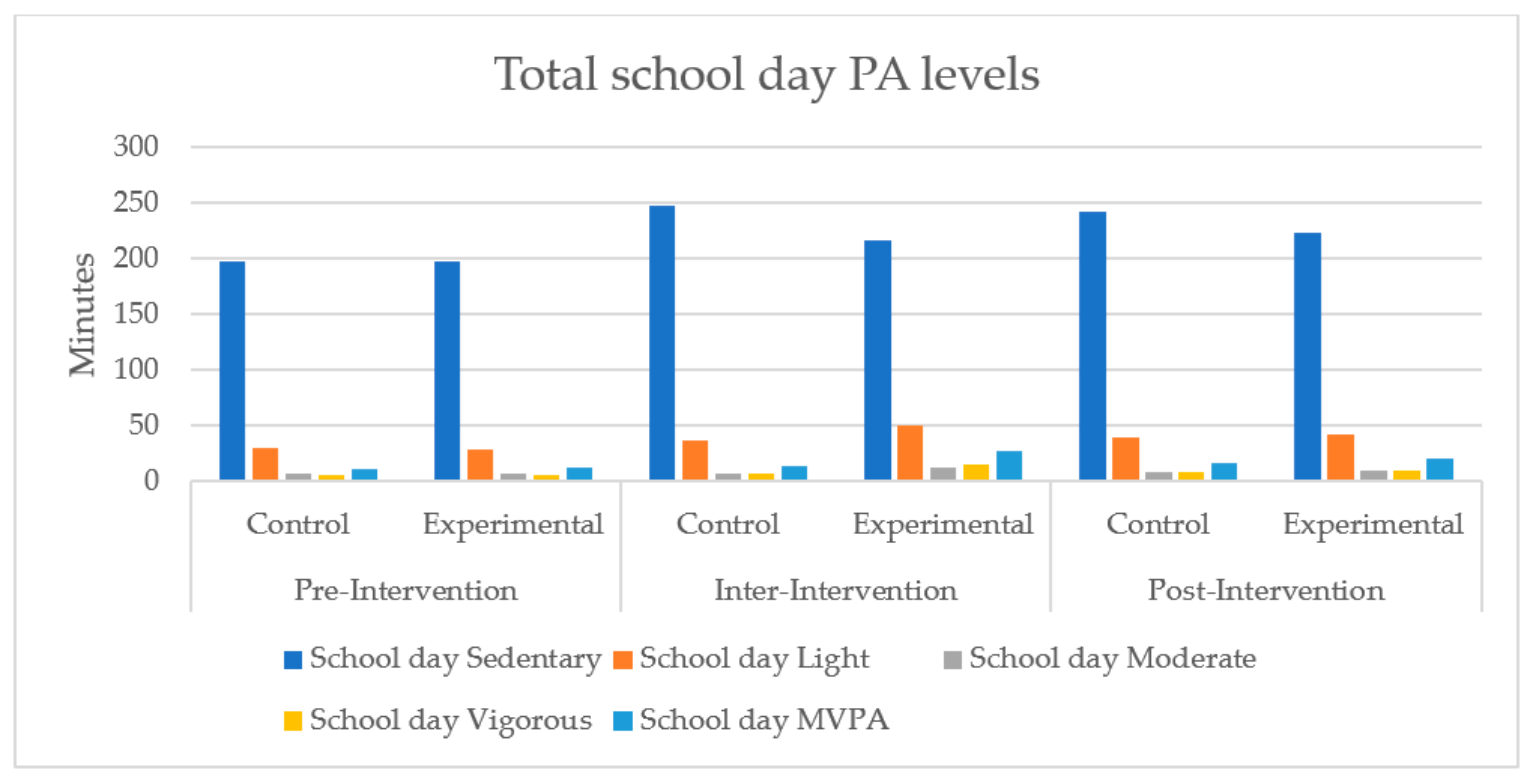

Figure 2. Levels of physical activity undertaken during the school day.

Finally, the results of the PA are presented that correspond to the ABs or PA undertaken during the school day in non-PE or recess periods, that is, the times of application of ABs or PA that the schoolchildren carry out independently of these periods. Regarding the intermediate data collection period, significant differences were found in the variables of moderate and vigorous PA, as well as in the combination of the latter (MVPA) (Table 2). However, once the program was completed, no significant values were observed in moderate PA, although significant values were observed in vigorous PA and MVPA. If both periods are compared for the experimental group by means of the Wilcoxon range test, significant differences were observed for the variables moderate PA $(p=0.000)$, vigorous PA $(p=0.000)$, and MVPA $(p=0.000)$ in favor of the intermediate period of the intervention. 
Table 2. Physical activity values developed with the application of the active breaks.

\begin{tabular}{|c|c|c|c|c|c|c|c|c|c|c|c|c|c|}
\hline & & \multicolumn{4}{|c|}{ Control Group } & \multicolumn{4}{|c|}{ Experimental Group } & \multirow{2}{*}{\multicolumn{2}{|c|}{$p$}} & \multirow{2}{*}{\multicolumn{2}{|c|}{$d$}} \\
\hline & & \multicolumn{2}{|c|}{ Inter $(n=22)$} & \multicolumn{2}{|c|}{ Post $(n=17)$} & \multicolumn{2}{|c|}{ Inter $(n=21)$} & \multicolumn{2}{|c|}{ Post $(n=21)$} & & & & \\
\hline & & $M$ & $S D$ & $M$ & $S D$ & $M$ & $S D$ & $M$ & $S D$ & Inter & Post & Inter & Post \\
\hline Moderate & (min/day) & 2.31 & 1.14 & 3.33 & 1.24 & 6.25 & 2.20 & 4.03 & 1.36 & $0.000^{* *}$ & 0.078 & 2.25 & 0.54 \\
\hline Vigorous & (min/day) & 1.58 & 0.84 & 2.73 & 1.36 & 7.22 & 2.59 & 4.22 & 1.44 & $0.000^{* *}$ & $0.002^{* *}$ & 2.93 & 1.06 \\
\hline MVPA & (min/day) & 3.87 & 1.86 & 6.06 & 2.56 & 13.48 & 3.97 & 8.25 & 2.60 & $0.000 * *$ & $0.006^{* *}$ & 3.10 & 0.85 \\
\hline
\end{tabular}

Note: $\mathrm{M}=$ mean; $\mathrm{SD}$ = standard deviation; $\mathrm{d}=$ effect size (Cohen); Inter = intermediate intervention measurement; Post $=$ post-test; ${ }^{*} p<0.05 ;{ }^{* *} p<0.01$; Moderate, Vigorous = physical activity levels (Evenson et al., 2008); MVPA = moderate to vigorous physical activity.

Table 3 shows the contribution to the $60 \mathrm{~min} /$ day MVPA recommendations of each of the activities carried out during a school day. As can be seen, the application of ABs made a contribution of $22.47 \%$ to the time recommended by the WHO. In the intermediate period, the total ABs performed at school in the experimental group reached $46.37 \%$ of the WHO recommendations, compared with $22.20 \%$ in the control group.

Table 3. Contributions expressed as a percentage of the different activities undertaken during a school day with respect to moderate to vigorous physical activity (MVPA) according to World Health Organization (WHO) recommendations.

\begin{tabular}{cccccccc}
\hline & \multicolumn{3}{c}{ Control Group (CG) } & \multicolumn{3}{c}{ Experimental Group (EG) } \\
\cline { 3 - 7 } & & Pre & Inter & Post & Pre & Inter & Post \\
\hline School day & CR 60 $\min (\%)$ & 19.37 & 22.20 & 27.43 & 20.6 & 46.37 & 33.71 \\
ABs & CR 60 $\mathrm{min}(\%)$ & - & 6.45 & 10.10 & - & 22.47 & 13.75 \\
PE & CR 60 $\mathrm{min}(\%)$ & 3.83 & 10.38 & 15.27 & 4.63 & 13.23 & 15.40 \\
Recess & CR 60 $\mathrm{min}(\%)$ & 11.82 & 9.28 & 9.36 & 11.58 & 13.73 & 11.53 \\
\hline
\end{tabular}

Note: Pre = pre-test; Inter $=$ intermediate measurement of intervention; Pos = post-test; School day = school day (9:00 am-14:00 pm); ABs = active break (in the control group physical activity (PA) conducted without regard to recess or PE); $\mathrm{PE}=$ physical education classes; Recess = integrated rest in the school day of $30 \mathrm{~min}$; $\mathrm{CR} 60 \mathrm{~min}(\%)=$ contribution to WHO recommendations of $60 \mathrm{~min} /$ day MVPA.

\section{Discussion}

The changes in PA in primary school children as a result of the implementation of a 17 week school intervention program were evaluated. The ABs significantly improved all the variables analyzed. They contributed to a reduction in physical sedentarism and to an increase in the levels of MVPA in accordance with stipulated health advice. The results were consistent with the higher effects of MVPA reported by previous research into ABs that also focused on the school day [13,35-37]. It was observed that the participating school children were sedentary for an average of $82.54 \%$ of the time in the case of the control group and $71.99 \%$ for the experimental group. The time spent engaged in MVPA reached $4.44 \%$ and $9.27 \%$, respectively.

A comparison with a study that was carried out looking at children between 10-12 years of age from several European countries [38] showed that the values of sedentary time obtained from both groups of the present investigation were higher than those of this research (approximately $65 \%$, with values of MVPA of approximately 5\%). These last data were similar for the control group; however, in the experimental group, it was observed that the percentage of time that the pupils spent engaged in MVPA was higher than that of the study of the population of European school children, indicating that the application of ABs contributed to a relative increase in the levels of MVPA in children of the primary school under investigation.

In reference to PE, the values obtained from the participants of the present study were lower than those in other pieces of research that indicated values of MVPA performance based on between 16-17 min per day [39-41]. On the other hand, they were similar to Calahorro-Cañada et al.'s [2] study and also to reviews on the subject $[42,43]$. 
With regard to school playtime, the values obtained in the control group in terms of MVPA were lower than those in another study that analyzed a school population in Spain [44], although these data were within the range (between two and seven minutes) employed in other studies of different nationalities and populations $[2,42,45-47]$. On the other hand, the results produced by the experimental group were superior, showing similar effects to some studies $[44,48]$, while they were inferior to those obtained from adolescents $(M=13.3 \pm 0.5)$ in another [49]. This could be because those students, over time, engaged in more MVPA during periods of unstructured classes (such as recesses). In this way, ABs may contribute indirectly to the increase in PA [50].

It was observed that, after the application of the intervention program, the values in MVPA dropped in the experimental group to values closer to those of the control group and, therefore, to the average of those of other studies. However, there were still significant differences in terms of sedentary time with respect to the control group and of light and moderate PA in favor of the experimental group. From this perspective, study of how the ABs affect MVPA [51] has suggested that increases in PA at specific moments of the school day can affect activities at other times; the conclusion is, therefore, that one of the effects of this type of intervention might be that it triggers greater positive motivation to engage in PA. Another possible explanation is that ABs allowed participants to increase their physical capacity and condition, and this allowed them to perform a greater amount of MVPA throughout the day. In this respect, there are studies showing that active participation in PE classes increases the chances of being less sedentary and more physically active in the educational environment and in other contexts [39,52].

In addition, it can be seen that, in this study, the ABs led to a significant increase in MVPA in terms of the analysis of different periods of the school day. In these times, some physical components were developed that led to longer periods within the school schedule in which more MVPA was undertaken, surpassing even PE classes. In other programs [53], the MVPA increased for approximately eight minutes per day with $\mathrm{ABs}$ of a duration of $45 \mathrm{~min}$, whereas in the present study, a difference with respect to the control group of almost 10 min was obtained with the application of four ABs per day with a duration of between five to $10 \mathrm{~min}$.

Physical activity (including games such as relays) of five to $10 \mathrm{~min}$ in mathematics or language classes contrasted with traditional classes and yielded an average of $5.89(S D=12.11)$ minutes of MVPA. There was a correlation of this increase in PA with the increase in attention or time spent on the task after its application, while in the control group, there was a cognitive decrease [54]. This evidence was confirmed [55] by applying $10 \mathrm{~min}$ ABs five times a week, proving that children accumulated significantly more MVPA than non-participants in the program, and that this was associated with an increase in time spent on subsequent academic work.

The WHO [1] advised that schools should try to attain $50 \%$ of its suggestions, that is, that they should perform $30 \mathrm{~min}$ of MVPA during the school day [56]. Physical activity levels in both the control and experimental groups did not meet the recommended minimum of $30 \mathrm{~min}$ during the time the children were in school, although the experimental group came close to the figure $(M=27.82 \pm 6.36)$ through the inclusion of ABs. There were also no minimum recommended indications of $60 \mathrm{~min} \mathrm{MVPA/day} \mathrm{to} \mathrm{ensure} \mathrm{healthy} \mathrm{states} \mathrm{in} \mathrm{children} \mathrm{[1],} \mathrm{so} \mathrm{these} \mathrm{interventions} \mathrm{should}$ be considered appropriate as a complement to other opportunities to increase children's PA [54], such as extracurricular sports activities, active ways of coming to and going from school, and so on.

Finally, the strengths of this study are based on the objective measurement of PA by accelerometry and the impact of ABs on different levels of PA throughout the school days. In addition, the degree of compliance with WHO recommendations and the contribution of the ABs to MVPA were verified. As has been shown, the ABs represented $22.47 \%$ of these daily PA recommendations, assuming higher levels than those provided during PE and recesses. Therefore, although their contribution in isolation may not be very high in terms of complying with WHO recommendations, their short duration in terms of application allows a greater amount of MVPA to accumulate than other activities of longer duration (such as PE and recesses). 
However, the study has several limitations, for example, in terms of the number of participating schools $(N=1)$ and the number of participants evaluated $(N=44)$, so these do not provide sufficient statistical robustness to carry out multivariate statistics [53]. Furthermore, the first week of measurement did not allow a direct comparison with the other two remaining weeks, since it was carried out during a reduced school day. In addition, this intervention only examined PA during school hours, that is, the children did not carry the accelerometers at other times. Evaluating these periods could provide relevant information to deepen the holistic understanding of the effects of $\mathrm{ABs}$ on the daily PA of students.

\section{Conclusions}

The effects of the AB program on PA levels were studied over four months. It is concluded that ABs led to an increase in the total MVPA registered during the school day, including an increase of PA levels in PE lessons and recesses. These data may be very useful in proposing intervention programs to increase physical-sports activity and thus to decrease physical sedentarism in schools.

Author Contributions: Conceptualization, J.A.M.-P., N.B.-P., G.T.-L., and A.V.-V.; methodology, J.A.M.-P.; software, J.A.M.-P. and A.V.-V.; validation, N.B.-P., G.T.-L., and A.V.-V.; formal analysis, J.A.M.-P., N.B.-P., G.T.-L., and A.V.-V.; investigation, J.A.M.-P.; resources, J.A.M.-P. and A.V.-V.; data curation, G.T.-L. and A.V.-V.; writing-original draft preparation, J.A.M.-P., N.B.-P., G.T.-L., and A.V.-V.; writing-review and editing, N.B.-P., G.T.-L., and A.V.-V.; visualization, J.A.M.-P., N.B.-P., G.T.-L., and A.V.-V.; supervision, N.B.-P., G.T.-L., and A.V.-V.; project administration, J.A.M.-P.; funding acquisition, J.A.M.-P. All authors have read and agreed to the published version of the manuscript.

Funding: This research received no external funding.

Acknowledgments: The authors are particularly grateful to all participants for their voluntary participation in the study.

Conflicts of Interest: The authors declare no conflict of interest.

\section{References}

1. World Health Organization. Global Recommendations on Physical Activity for Health; WHO: Ginebra, Switzerland, 2010.

2. Calahorro-Cañada, F.; Torres-Luque, G.; López-Fernandez, I.; Carnero, E.A. Fractional analysis of physical activity in school children. Rev. Psicol. Deporte 2015, 24, 373-379.

3. Calahorro-Cañada, F.; Torres-Luque, G.; López-Fernández, I.; Carnero, E.A. Is physical education an effective way to increase physical activity in children with lower cardiorespiratory fitness? Scand. J. Med. Sci. Sport 2016, 27, 1417-1422. [CrossRef] [PubMed]

4. Downing, K.L.; Hinkley, T.; Salmon, J.; Hnatiuk, J.A.; Hesketh, K.D. Do the correlates of screen time and sedentary time differ in preschool children? BMC Public Health 2017, 17, 285. [CrossRef]

5. Jalali-Farahani, S.; Amiri, P.; Abbasi, B.; Karimi, M.; Cheraghi, L.; Daneshpour, M.S.; Aziz, F. Maternal characteristics and incidence of overweight obesity in children: A 13 year follow up study in an eastern mediterranean population. Matern. Child Health J. 2017, 5, 1211-1220. [CrossRef] [PubMed]

6. Lou, D. Sedentary Behaviors and Youth: Current Trends and the Impact on Health; Active Living Research: San Diego, CA, USA, 2014.

7. Chillón, P.; Evenson, K.R.; Vaughn, A.; Ward, D.S. A systematic review of interventions for promoting active transportation to school. Int. J. Behav. Nutr. Phys. Act. 2011, 8, 10. [CrossRef] [PubMed]

8. Andrade-Gómez, E.; García-Esquinas, E.; Ortolá, R.; Martínez-Gómez, D.; Rodríguez-Artalejo, F. Watching TV has a distinct sociodemographic and lifestyle profile compared with other sedentary behaviors: A nationawide population-based study. PLoS ONE 2017, 12, e0188836. [CrossRef] [PubMed]

9. Turner, L.; Chaloupka, F.J. Reach and implementation of physical activity breaks and active lessons in elementary school classrooms. Health Educ. Behav. 2017, 44, 370-375. [CrossRef]

10. McMullen, J.M.; Martin, R.; Jones, J.; Murtagh, E.M. Moving to learn Ireland-Classroom teachers' experiences of movement integration. Teach. Teach. Educ. 2016, 60, 321-330. [CrossRef] 
11. Drummy, C.; Murtagh, E.M.; McKee, D.P.; Breslin, G.; Davison, G.W.; Murphy, M.H. The effect of a classroom activity break on physical activity levels and adiposity in primary school children. J. Paediatr. Child Health 2016, 52, 745-749. [CrossRef]

12. Martin, R.; Murtagh, E.M. Preliminary findings of Active Classrooms: An intervention to increase physical activity levels of primary school children during class time. Teach. Teach. Educ. 2015, 52, 113-127. [CrossRef]

13. Riley, N.; Lubans, D.R.; Holmes, K.; Morgan, P.J. Findings from the EASY Minds cluster randomized controlled trial: Evaluation of a physical activity integration program for mathematics in primary schools. J. Phys. Act. Health 2016, 13, 198-206. [CrossRef] [PubMed]

14. Riley, N.; Lubans, D.R.; Holmes, K.; Hansen, V.; Gore, J.; Morgan, P.J. Movement-based mathematics: Enjoyment and engagement without compromising learning through the EASY Minds program. Eurasia Journal of Mathematics. Sci. Technol. Educ. 2017, 13, 1653-1673. [CrossRef]

15. DuBose, K.D.; Mayo, M.S.; Gibson, C.A.; Green, J.L.; Hill, J.O.; Jacobsen, D.J.; Donnelly, J.E. Physical activity across the curriculum (PAAC): Rationale and design. Contemp. Clin. Trials 2008, 29, 83-93. [CrossRef]

16. Honas, J.J.; Washburn, R.A.; Smith, B.K.; Greene, J.L.; Donnelly, J.E. Energy expenditure of the physical activity across the curriculum intervention. Med. Sci. Sports Exerc. 2008, 40, 1501-1505. [CrossRef] [PubMed]

17. Honas, J.J.; Willis, E.A.; Herrmann, S.D.; Greene, J.L.; Washburn, R.A.; Donnelly, J.E. Energy expenditure and intensity of classroom physical activity in elementary school children. J. Phys. Act. Health 2016, 13, S53-S56. [CrossRef]

18. Liu, A.; Hu, X.; Ma, G.; Cui, Z.; Pan, Y.; Chang, S.; Chen, C. Evaluation of a classroom-based physical activity promoting programme. Obes. Rev. 2008, 9, 130-134. [CrossRef]

19. Cardon, G.; De Clercq, D.; De Bourdeaudhuij, I.; Breithecker, D. Sitting habits in elementary schoolchildren: A traditional versus a "Moving school". Patient Educ. Couns. 2004, 54, 133-142. [CrossRef]

20. Erwin, H.E.; Abel, M.G.; Beighle, A.; Beets, M.W. Promoting children's health through physically active math classes: A pilot study. Health Promot. Pract. 2011, 12, 244-251. [CrossRef]

21. Stewart, G.; Webster, C.A.; Stodden, D.F.; Brian, A.; Egan, C.A.; Weaver, R.G. The association of children's participation in school physical activity opportunities with classroom conduct. Int. J. Edu. Res. 2019, 97, 22-28. [CrossRef]

22. Carlson, J.A.; Engelberg, J.K.; Cain, K.L.; Conway, T.L.; Mignano, A.M.; Bonilla, E.A.; Sallis, J.F. Implementing classroom physical activity breaks: Associations with student physical activity and classroom behavior. Prev. Med. 2015, 81, 67-72. [CrossRef]

23. Godwin, K.E.; Almeda, M.V.; Seltman, H.; Kai, S.; Skerbetz, M.D.; Baker, R.S.; Fisher, A.V. Off-task behavior in elementary school children. Learn. Instr. 2016, 44, 128-143. [CrossRef]

24. Olson, M. TABATA: It's a HIIT! ACSM'S Health Fit. J. 2014, 18, 17-24. [CrossRef]

25. Tabata, I.; Nishimura, K.; Kouzaki, M.; Hiral, Y.; Ogita, F.; Miyachi, M.; Yamamoto, K. Effects of moderate-intensity endurance and high-intensity intermittent training on anaerobic capacity and VO2max. Med. Sci. Sports Exerc. 1996, 28, 1327-1330. [CrossRef]

26. Mayer, J.D.; Salovey, P. What is emotional intelligence? In Emotional Development and Emotional Intelligence: Implications for Educators; Salovey, P., Sluyter, D., Eds.; Basic Books: New York, NY, USA, 1997; pp. 3-31.

27. Ruiz-Aranda, D.; Cabello-González, R.; Palomera-Martín, R.; Extremera-Pacheco, N.; Salguero-Noguera, J.M.; Fernández-Berrocal, P. Programa Intemo. Guía Para Mejorar la Inteligencia Emocional de los Adolescentes [Intemo Programme. Guide to Improve Emotional Intelligent in Adolescents]; Ediciones Pirámide: Madrid, Spain, 2013. [CrossRef]

28. Fernández-Río, J. The cooperative learning cycle: A guide to effectively implement cooperative learning in physical education. Retos 2017, 32, 244-249.

29. Delisle-Nyström, C.; Pomeroy, J.; Henriksson, P.; Forsum, E.; Ortega, F.B.; Maddison, R.; Migueles, J.H.; Löf, M. Evaluation of the wrist-worn ActiGraph wGT3x-BT for estimating activity energy expenditure in preschool children. Eur. J. Clin. Nutr. 2017, 71, 1212-1217. [CrossRef]

30. Santos-Lozano, A.; Marín, P.J.; Torres-Luque, G.; Ruiz, J.R.; Lucía, A.; Garatachea, N. Technical variability of the GT3X accelerometer. Med. Eng. Phys. 2012, 34, 787-790. [CrossRef]

31. Evenson, K.R.; Catellier, D.J.; Gill, K.; Ondrak, K.S.; McMurray, R.G. Calibration of two objective measures of physical activity for children. J. Sport Sci. 2008, 26, 1557-1565. [CrossRef] [PubMed] 
32. Calahorro-Cañada, F.C.; Torres-Luque, G.; López-Fernández, I.; Álvarez-Carnero, E. Physical activity levels and accelerometry: Recommendations and patterns in school-aged subjects. Cuad. Psicol. Deporte 2014, 14, 129-140. [CrossRef]

33. Mohd-Razali, N.; Bee-Wah, Y. Power comparisons of shapiro-wilk, kolmogorov-smirnov, lilliefors and anderson-darling tests. J. Stat. Model. Anal. 2011, 2, 21-33.

34. Cohen, J. A power primer. Psychol. Bull. 1992, 112, 155-159. [CrossRef]

35. Grieco, L.A.; Jowers, E.M.; Errisuriz, V.L.; Bartholomew, J.B. Physically active vs. sedentary academic lessons: A dose response study for elementary student time on task. Prev. Med. 2016, 89, 98-103. [CrossRef] [PubMed]

36. Mullender-Wijnsma, M.J.; Hartman, E.; de Greeff, J.W.; Bosker, R.J.; Doolaard, S.; Visscher, C. Moderate-to-vigorous physically active academic lessons and academic engagement in children with and without a social disadvantage: A within subject experimental design. BMC Public Health 2015, 15, 404. [CrossRef]

37. Vazou, S.; Saint-Maurice, P.; Skrade, M.; Welk, G. Effect of Integrated Physical Activities with Mathematics on Objectively Assessed Physical Activity. Children 2018, 5, 140. [CrossRef] [PubMed]

38. van Stralen, M.M.; Yıldırım, M.; Wulp, A.; Te Velde, S.J.; Verloigne, M.; Doessegger, A.; Chinapaw, M.J. Measured sedentary time and physical activity during the school day of European 10-to 12-year-old children: The ENERGY project. J. Sci. Med. Sport 2014, 17, 201-206. [CrossRef] [PubMed]

39. Chen, S.; Kim, Y.; Gao, Z. The contributing role of physical education in youth's daily physical activity and sedentary behavior. BMC Public Health 2014, 14, 110. [CrossRef] [PubMed]

40. Martínez-Martínez, J.; Contreras-Jordán, O.R.; Aznar-Laín, S.; Lera-Navarro, A. Children's physical activity levels measured by accelerometer: All day physical activity vs physical education classes. Rev. Psicol. Deporte 2012, 21, 117-123.

41. Meyer, U.; Roth, R.; Zahner, L.; Gerber, M.; Puder, J.; Hebestreit, H.; Kriemler, S. Contribution of physical education to overall physical activity. Scand. J. Med. Sci. Sports 2011, 23, 600-606. [CrossRef]

42. Fairclough, S.J.; Stratton, G. Physical activity levels in middle and high school physical education: A review. Pediatr. Exer. Sci. 2005, 17, 217-236. [CrossRef]

43. Hollis, J.L.; Williams, A.J.; Sutherland, R.; Campbell, E.; Nathan, N.; Wolfenden, L.; Wiggers, J. A systematic review and meta-analysis of moderate-to-vigorous physical activity levels in elementary school physical education lessons. Prev. Med. 2016, 86, 34-54. [CrossRef]

44. Martínez-Martínez, J.; Aznar-Laín, S.; Contreras-Jordán, O. The recess school space and time as a healthy opportunity. Rev. Int. Med. Cienc. Act. Fis. Dep. 2015, 15, 419-432. [CrossRef]

45. Fairclough, S.J.; Beighle, A.; Erwin, H.; Ridgers, N.D. School day segmented physical activity patterns of high and low active children. BMC Public Health 2012, 12, 406. [CrossRef]

46. Martínez-Gómez, D.; Veiga, O.L.; Zapatera, B.; Gomez-Martinez, S.; Martinez, D.; Marcos, A. Physical Activity During High School Recess in Spanish Adolescents: The AFINOS Study. J. Phys. Act. Health 2013, 11, 1194-1201. [CrossRef] [PubMed]

47. Mota, J.; Silva, P.; Santos, M.P.; Ribeiro, J.C.; Oliveira, J.; Duarte, J.A. Physical activity and school recess time: Differences between the sexes and the relationship between children's playground physical activity and habitual physical activity. J. Sports Sci. 2005, 23, 269-275. [CrossRef] [PubMed]

48. Frago-Calvo, J.M. Niveles de Actividad Física en Escolares de Educación Primaria: Actividad Física Habitual, Clases de Educación Física y Recreos [Physical Activity Levels in Primary Education Students: Regular Physical Activity, Physical Education Lessons and Recesses]. Unpublished. Ph.D. Thesis, Universidad de Zaragoza, Zaragoza, Spain, 2014.

49. Martínez-Gómez, D.; Calabro, M.A.; Welk, G.J.; Marcos, A.; Veiga, O.L. Reliability and validity of a school recess physical activity recall in Spanish youth. Pediatr. Exerc. Sci. 2010, 22, 218-230. [CrossRef]

50. van der Niet, A.G.; Smith, J.; Oosterlaan, J.; Scherder, E.J.; Hartman, E.; Visscher, C. Effects of a cognitively demanding aerobic intervention during recess on children's physical fitness and executive functioning. Pediatr. Exerc. Sci. 2016, 28, 64-70. [CrossRef]

51. Wilson, A.N.; Olds, T.; Lushington, K.; Parvazian, S.; Dollman, J. Active school lesson breaks increase daily vigorous physical activity, but not daily moderate to vigorous physical activity in elementary school boys. Pediatr. Exerc. Sci. 2017, 29, 145-152. [CrossRef] 
52. Gao, Z.; Pope, Z.; Lee, J.E.; Stodden, D.; Roncesvalles, N.; Pasco, D.; Feng, D. Impact of exergaming on young children's school day energy expenditure and moderate-to-vigorous physical activity levels. J. Sport Health Sci. 2017, 6, 11-16. [CrossRef]

53. Seljebotn, P.H.; Skage, I.; Riskedal, A.; Olsen, M.; Kvalø, S.E.; Dyrstad, S.M. Physically active academic lessons and effect on physical activity and aerobic fitness. The Active School study: A cluster randomized controlled trial. Prev. Med. Rep. 2019, 13, 183-188. [CrossRef]

54. Bartholomew, J.B.; Golaszewski, N.M.; Jowers, E.; Korinek, E.; Roberts, G.; Fall, A.; Vaughn, S. Active learning improves on-task behaviors in 4th grade children. Prev. Med. 2018, 111, 49-54. [CrossRef]

55. Szabo-Reed, A.N.; Willis, E.A.; Lee, J.; Hillman, C.H.; Washburn, R.A.; Donnelly, J.E. Impact of Three Years of Classroom Physical Activity Bouts on Time-on-Task Behavior. Med. Sci. Sports Exerc. 2017, 49, 2343-2350. [CrossRef]

56. Pate, R.R.; Davis, M.G.; Robinson, T.N.; Stone, E.J.; McKenzie, T.L.; Young, J.C. Promoting physical activity in children and youth: A leadership role for schools: A scientific statement from the American Heart Association Council on Nutrition, Physical Activity, and Metabolism (Physical Activity Committee) in collaboration with the Councils on Cardiovascular Disease in the Young and Cardiovascular Nursing. Circulation 2006, 114, 1214-1224. [CrossRef] [PubMed]

(C) 2020 by the authors. Licensee MDPI, Basel, Switzerland. This article is an open access article distributed under the terms and conditions of the Creative Commons Attribution (CC BY) license (http://creativecommons.org/licenses/by/4.0/). 